\title{
Simulating the diurnal cycle of rainfall in global climate models: resolution versus parameterization
}

\author{
Paul A. Dirmeyer • Benjamin A. Cash · James L. Kinter III • Thomas Jung • \\ Lawrence Marx • Masaki Satoh • Cristiana Stan • Hirofumi Tomita • \\ Peter Towers • Nils Wedi - Deepthi Achuthavarier • Jennifer M. Adams • \\ Eric L. Altshuler · Bohua Huang • Emilia K. Jin · Julia Manganello
}

Received: 11 March 2011 / Accepted: 15 June 2011/Published online: 25 June 2011

(C) The Author(s) 2011. This article is published with open access at Springerlink.com

\begin{abstract}
The effects of horizontal resolution and the treatment of convection on simulation of the diurnal cycle of precipitation during boreal summer are analyzed in several innovative weather and climate model integrations. The simulations include: season-long integrations of the Nonhydrostatic Icosahedral Atmospheric Model (NICAM) with explicit clouds and convection; year-long integrations of the operational Integrated Forecast System (IFS) from the European Centre for Medium-range Weather Forecasts at three resolutions $(125,39$ and $16 \mathrm{~km})$; seasonal simulations of the same model at $10 \mathrm{~km}$ resolution; and seasonal simulations of the National Center for Atmospheric Research (NCAR) low-resolution climate model with and without an embedded two-dimensional cloud-resolving model in each grid box. NICAM with explicit convection simulates best
\end{abstract}

P. A. Dirmeyer $(\bowtie) \cdot$ B. A. Cash · J. L. Kinter III · L. Marx ·

C. Stan - D. Achuthavarier - J. M. Adams .

E. L. Altshuler · B. Huang · E. K. Jin · J. Manganello

Center for Ocean-Land-Atmosphere Studies,

Calverton, MD, USA

e-mail: dirmeyer@cola.iges.org

J. L. Kinter III · B. Huang · E. K. Jin

George Mason University, Fairfax, VA, USA

T. Jung $\cdot$ P. Towers $\cdot$ N. Wedi

The European Centre for Medium-Range Weather Forecasts, Reading, UK

M. Satoh · H. Tomita

Research Institute for Global Change/

Japan Agency for Marine-Earth Science and Technology,

Yokohama, Japan

M. Satoh

Atmosphere and Ocean Research Institute,

The University of Tokyo, Chiba, Japan the phase of the diurnal cycle, as well as many regional features such as rainfall triggered by advancing sea breezes or high topography. However, NICAM greatly overestimates mean rainfall and the magnitude of the diurnal cycle. Introduction of an embedded cloud model within the NCAR model significantly improves global statistics of the seasonal mean and diurnal cycle of rainfall, as well as many regional features. However, errors often remain larger than for the other higher-resolution models. Increasing resolution alone has little impact on the timing of daily rainfall in IFS with parameterized convection, yet the amplitude of the diurnal cycle does improve along with the representation of mean rainfall. Variations during the day in atmospheric prognostic fields appear quite similar among models, suggesting that the distinctive treatments of model physics account for the differences in representing the diurnal cycle of precipitation.

Keywords Precipitation - Diurnal cycle - GCM · Climate model $\cdot$ Parameterization $\cdot$ Resolution

\section{Introduction}

Diurnal variations in the water cycle are important, as the day is the shortest regular period over which the energy cycle oscillates, and the water and energy cycles are linked directly via evaporation (Polcher 2004). The daily response of evaporation and the growth of the planetary boundary layer of the atmosphere to the surface heating during daylight hours is well established (e.g., Stull 1988; Ek and Holstlag 2004). In many parts of the world, a pronounced daily cycle of rainfall exists over land. This tends to fall into one of three categories: (1) rainfall triggered over relatively flat terrain in a warm and humid atmosphere as a result of local convective instability, (2) thermo- 
mechanically triggered convection over mountain ranges that promote elevated heating of the troposphere, upslope circulations and organized convergence, and (3) convection triggered as a result of differential heating between open water and land and the daily cycle of land and sea/lake breezes near coastlines or over islands.

Examples of the first category are found over the interior of the Amazon basin in most seasons, and during local summer over the southeastern US, much of southern Africa, and the La Plata basin of South America (e.g., Dai et al. 1999; Sorooshian et al. 2002). Orographically-triggered convection prominently occurs along the front range of the Rocky Mountains, particularly in Colorado, and typically propagates eastward for many hours as an organized line of convection (Riley et al. 1987). This phenomenon is not limited to the US, however, and has been found to occur on the eastern and southern margins of the Tibetan Plateau, the eastern slopes of the Andes into the Pampas and Bolivia, Ethiopia, and out of the highlands surrounding the Great Rift Valley in Africa. A remarkable large-scale sea-breeze effect is found along the tropical Atlantic coast of South America at nearly all times of year (e.g., Garreaud and Wallace 1997; Sorooshian et al. 2002), although many more local examples exist. There are also diurnal patterns in precipitation over the ocean, particularly near continents (Nesbitt and Zipser 2003).

These prominent diurnal rainfall features pose a major challenge for global circulation models (GCMs) of the atmosphere used to forecast and study weather and climate. These models were initially developed decades ago when limitations on computing power dictated that they resolve the earth's surface and atmosphere as stacks of homogeneous slabs hundreds of kilometers on a side. In order to represent the effect that much smaller scale processes such as cloud formation, surface friction and turbulent mixing have on the atmosphere at those broad scales, approximations were introduced in the form of sub-grid parameterizations of physical processes. As computing power has increased, these models have grown more complex in their intrinsic physics and are run at ever higher resolutionsnow typically tens of kilometers across a grid box. However, for global models, the horizontal resolution is still sufficiently coarse that the hydrostatic approximation is successfully employed in the dynamical predictive equations, and physical processes such as radiation, convection and turbulence remain parameterized. Additionally, coarse resolutions mean that only the broadest orographic features are "felt" at the lower boundary of the atmosphere. Steep topography, individual mountain peaks, scarps, etc., are unresolved, and are parameterized as sub-grid scale orographic drag. The partitioning between explicitly resolved and parameterized features of the terrain varies with the horizontal resolution of the model. Spatial resolutions from a few hundred meters to a few kilometers would be necessary to justifiably begin to represent most key physical processes explicitly, forgoing parameterizations.

One consequence of the bulk representation of fine-scale processes in the form of parameterizations is that most weather and climate models tend to phase-lock their convective rainfall to local noon (Dai 2006). GCMs exhibit peak convection over land near local noon, although some employ modifications to their parameterizations that can delay the onset of convection, producing somewhat more realistic afternoon maxima. But these adaptations tend to apply a uniform adjustment everywhere, and still fail to capture regional variations adequately.

In this paper, we explore how three recent evolutions in global seasonal-scale modeling, each allowed by increasing computing power, affect the representation of the diurnal cycle of rainfall: greatly increased horizontal resolution in a weather forecast model with parameterized convection; a non-hydrostatic cloud-resolving model run globally; and a climate model with an imbedded cloud-resolving model used as a parameterization of convection. We expect each of these innovations to have positive effects on the simulation of the diurnal cycle. We explore the character of these effects and compare between models.

The very-high resolution global model simulations described below were performed in response to a call for a "revolution" in seamless weather and climate modeling made at the World Modeling Summit, held in May 2008 in Reading, UK (Shukla et al. 2009). To address this challenge, the National Science Foundation dedicated a Cray XT-4 supercomputer housed at the University of Tennessee's National Institute for Computational Sciences (NICS) to climate research for a period of 6 months. The Athena Project (Kinter III et al. 2011) brought together an international team to determine the feasibility of using dedicated supercomputing resources to rapidly accelerate progress in modeling climate variability to decadal and longer time scales. This project has focused on two GCMs. The first is the very high resolution Japan Agency for Marine-Earth Science and Technology (JAMSTEC) and the University of Tokyo Non-hydrostatic ICosahedral Atmospheric Model (NICAM) with explicit physics and non-hydrostatic dynamics, that heretofore has only been run in synoptic weather mode (simulations no longer than 10 days). The other is the European Centre for Mediumrange Weather Forecasts (ECMWF) Integrated Forecast System (IFS) operational weather and seasonal forecast model, which is renowned for being a global leader in terms of predictive skill and high spatial resolutions that nevertheless is still in the realm of parameterized convection. IFS has been run at a range of spatial resolutions spanning more than two orders of magnitude in grid cell area. 
In addition, collaborations with the Center for Multiscale Modeling of Atmospheric Processes bring to bear two versions of a third model, the widely-used National Center for Atmospheric Research (NCAR) Community Climate System Model (CCSM), one version in a standard climate configuration run at low resolution, and a second (SPCCSM) containing a "super-parameterized" convection scheme that embeds a cloud-resolving scheme within a coarse resolution atmospheric model.

With this suite of GCMs, described in detail in Sect. 2, we have the opportunity to investigate the effects of both model resolution and the representation of convective processes on the simulation of the diurnal cycle of rainfall across the globe. Although not every possible comparison of resolution or parameterization can be cleanly compared, this suite of simulations offers many unique opportunities for study. Section 3 describes the validation data sets used, as well as the techniques used to extract the diurnal harmonic from the various data sets. Results are presented in Sect. 4, and conclusions are given in Sect. 5.

\section{Models}

We use data from several unique model simulations designed to examine the effects on the representation of climate at very high spatial resolution of some or all aspects of the atmosphere. Simulations were performed with the IFS (Molteni et al. 1996; ECMWF 2009), and NICAM (Satoh et al. 2008) atmospheric GCMs forced with observed SSTs and sea ice. In addition, we examine simulations from two coupled configurations of CCSM (Collins et al. 2006). Table 1 shows the key characteristics of the global atmospheric models used in this study, which are discussed below.

\subsection{IFS}

Operationally, IFS is integrated for medium-range weather forecasts (up to 10 days) at a horizontal spectral truncation of T1279, which translates on the reduced Gaussian grid to a grid spacing of about $16 \mathrm{~km}$. There are 91 levels in the vertical. Monthly forecasts with the model atmosphere coupled to the Hamburg Ocean Primitive Equation (HOPE; Wolff et al. 1997) model are conducted with the atmosphere configured at T159 (nominally a $125 \mathrm{~km}$ reduced Gaussian grid) with 62 vertical levels.

For the Athena Project, model version CY32r3 of the IFS was integrated at several horizontal resolutions including the operational ones mentioned above (T159 or $125 \mathrm{~km}$ grid, T511 or $39 \mathrm{~km}$ grid, T1279 or $16 \mathrm{~km}$ grid, and T2047 or $10 \mathrm{~km}$ grid). For the lowest three resolutions, 47 13-month hindcasts were carried out, initialized on 1 November of each year beginning with 1960. For the T2047 simulations examined here, 13-month hindcasts are limited to 19 years (1989-2007). No changes to parameterizations were made in these different model resolutions, and the operational version of the code mentioned above is used for each resolution. Internal to the code, there is a resolution dependent term in the convective adjustment time that asymptotically approaches the ratio of cloud depth to cloud-average updraft velocity as resolution increases. At T159, it is 2.66 times this ratio, and at T2047 it is 1.13 times. No tuning was performed to improve the performance of IFS for this application, but of course, the model is the product of much development work to optimize its operational application. All resolutions use the same bulk mass flux convection scheme of Tiedtke (1989) and the same cloud microphysics and other parameterizations (ECMWF 2009). Physical parameterizations in IFS are constantly evolving, but recent implementations and
Table 1 Key characteristics of the global atmospheric models used

\begin{tabular}{|c|c|c|c|}
\hline Model & $\begin{array}{l}\text { Horizontal } \\
\text { resolution }(\mathrm{km})\end{array}$ & Convection & PBL \\
\hline IFS T159 & 125 & $\begin{array}{l}\text { Parameterized (Bechtold et al. 2008; } \\
\text { Jung et al. 2010) }\end{array}$ & $\begin{array}{l}\text { Bechtold et al. (2008) and Jung } \\
\text { et al. (2010) }\end{array}$ \\
\hline IFS T511 & 39 & & \\
\hline IFS T1279 & 16 & & \\
\hline IFS T2047 & 10 & & \\
\hline NICAM & 7 & $\begin{array}{l}\text { Explicit Cloud-resolving (Oouchi et al. } \\
\text { 2009a, b; Tomita 2008) }\end{array}$ & $\begin{array}{l}\text { Nakanishi and Niino (2006) and } \\
\text { Noda et al. (2010) }\end{array}$ \\
\hline CCSM T42 & $\sim 300$ & $\begin{array}{l}\text { Parameterized (Zhang and McFarlane } \\
\text { 1995) }\end{array}$ & Holtslag and Boville (1993) \\
\hline SPCCSM & $\sim 300$ & $\begin{array}{l}\text { Super-parameterized cloud-resolving } \\
(4 \mathrm{~km} \text {; Khairoutdinov et al. 2005) }\end{array}$ & \\
\hline
\end{tabular}


Fig. 1 Mean JJA precipitation from GPCP (lower right; $\mathrm{mm} /$ d), and the errors relative to GPCP for the various global model integrations
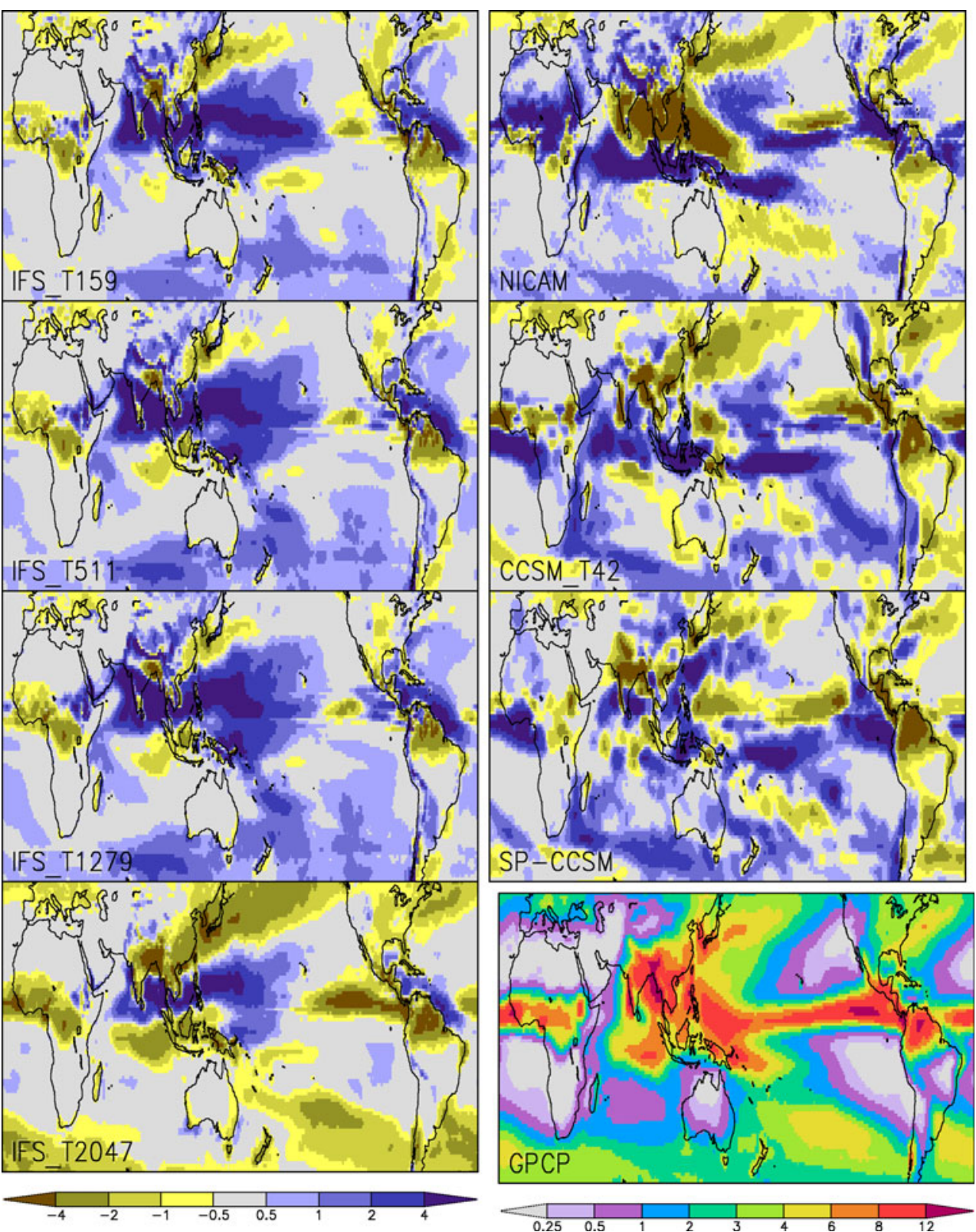

changes that affect this model version are documented by Bechtold et al. (2008) and Jung et al. (2010). Sea surface temperature (SST) boundary conditions are the $1.125^{\circ}$ monthly data before 1990, and weekly data beginning in 1990, that were used for the ERA-40 reanalysis (Uppala et al. 2005). They have been interpolated in time linearly, and in space to each GCM resolution's grid. Daily SSTs from the ECMWF operational system are used beginning in 2002.

\subsection{NICAM}

NICAM explicitly resolves cloud processes and is nonhydrostatic as its name implies. There are 40 levels in the vertical. The simulations with NICAM were on a $7-\mathrm{km}$ icosahedral grid (G-level 10) spacing, and were only performed for boreal summers (2001-2009 excluding 2003). Note that boreal summer only runs were also conducted with three of the IFS resolutions, and there was no appreciable difference in the precipitation statistics for seasonal versus longer runs. The 7-km grid spacing of NICAM is likely too coarse for a cloud-resolving model (Weisman et al. 1997; Bryan et al. 2003), but was the highest that was computationally feasible for the resources available in the Athena project. SST boundary conditions for the NICAM integrations are from the daily quarter-degree Reynolds analyses (Reynolds et al. 2007). Physics schemes are the same as those used by Oouchi et al. (2009a, b) who 
analyzed a $7 \mathrm{~km}$-spacing 3-month experiment with NICAM, except that the cloud microphysics scheme here is the 6-category single moment bulk scheme, NSW6 (Tomita 2008). The land model is also upgraded to the Simple Biosphere ( $\mathrm{SiB}$ ) type model, MATSIRO (Takata et al. 2003).

These are also the longest integrations of either NICAM or IFS at such high resolutions, and the first time that either model was run in the United States. Note that IFS was forced with SSTs that are 4-5 times coarser than NICAM, and at a much coarser temporal resolution for most of the integration period. This may have an effect on the precipitation statistics over oceans in regions with sharp SST gradients or rapid fluctuations.

\subsection{CCSM and SP-CCSM}

Version 3.0 of CCSM (Collins et al. 2006) was integrated at a horizontal resolution of T42 $(\sim 300 \mathrm{~km})$ for 4 months beginning 1 May, with atmosphere and ocean states initialized from an ENSO-neutral year within a 20 year long coupled simulation. 3-hourly output data were saved. The atmospheric model has the shallow convective scheme of Hack (1994) and deep convection of Zhang and McFarlane (1995). The model has an explicit, non-local boundary layer parameterization including calculation of boundary level depth from the gradient Richardson number (Holtslag and Boville 1993).

The same simulation was repeated with SP-CCSM (Stan et al. 2010). SP-CCSM replaces the convective parameterization with a two-dimensional east-west oriented cloud-resolving model at a horizontal resolution of $4 \mathrm{~km}$. This is embedded in every grid box with periodic boundary conditions, and run to explicitly represent cloud and convection processes (Khairoutdinov et al. 2005). At this time, CCSM 3.0 is the most recent version of CCSM to have the super-parameterization of convection implemented, tested and published-similar implementations have been done with older versions of NCAR and other models (e.g., Tao et al. 2009). The super-parameterization is computationally expensive, increasing run time by a factor of 100. Unlike the Athena Project GCM simulations described above, the CCSM simulations are coupled ocean-atmosphere integrations.

\section{Data and methods}

Monthly mean rainfall is validated against the Global Precipitation Climatology Project (GPCP) Version 2 Combined Precipitation Data Set (Adler et al. 2003). To determine the mean phase and amplitude of the diurnal cycle as a function of space and month, we use the Tropical
Rainfall Measuring Mission (TRMM) 3B42 global 3-hourly gridded precipitation estimates for 1998-2009 (Huffman et al. 2007), and the CMORPH 3-hourly precipitation estimates (Joyce et al. 2004). These diurnal cycle resolving satellite-based precipitation estimates have systematic errors relative to gauge-based gridded products (Tian et al. 2008; Zeweldi and Gebremichael 2009), but provide global coverage except over high latitudes. For purposes of validating the amplitude of the diurnal harmonic of precipitation, we scale the magnitude of rainfall estimated from TRMM and CMOPRH by the ratio of the GPCP monthly mean precipitation to the monthly mean from each of the two satellite estimates.

The Modern Era Retrospective-Analysis for Research and Applications (MERRA, Bosilovich 2008) is used as a baseline for the validation of the diurnal cycle of meteorological fields. MERRA has an improved simulation of the water cycle relative to other reanalysis models, which has led to superior simulation of key aspects of precipitation (Bosilovich et al. 2008).

Precipitation output from NICAM is written hourly, but the output from IFS is totaled every $6 \mathrm{~h}$, and CCSM output is 3-hourly. At each grid point, the phase and amplitude of the diurnal cycle of precipitation are calculated from observed and model data depending on time interval of the data. The phase is represented as the local hour of peak precipitation, and is calculated on a month-by-month basis. Details of the estimation of phase and magnitude for the various data sets are given in the Appendix.

\section{Results}

\subsection{Global statistics}

Because several of the models are run only for boreal summer, our analysis is confined to June-August (JJA). Figure 1 shows the mean rainfall rate during JJA from GPCP observations from 1979 to 2008, and the errors of each model relative to GPCP. For this figure and the results presented in Table 2, all data have been interpolated to a regular grid in the zonal direction with 320 grid boxes, and 160 Gaussian latitudes in the meridional direction, which matches the T159 IFS resolution at the equator (recall that IFS data are reported on a reduced Gaussian grid).

The left column of the table shows the errors for the various resolutions of IFS, with resolution increasing from top to bottom. As resolution increases, the area covered by wet biases gradually grows, until the interval from T1279 to $\mathrm{T} 2047$, where there is a marked decrease in rainfall over most locations. The basic patterns are very similar, however, among these four resolutions. There tends to be an underrepresentation of rainfall over the tropical continents, 
Table 2 Statistics of mean seasonal precipitation compared to GPCP for JJA of the model simulations between $50^{\circ} \mathrm{S}$ and $50^{\circ} \mathrm{N}$

RMSE units are mm/d

\begin{tabular}{llllllll}
\hline & \multicolumn{2}{l}{ RMSE } & & & \multicolumn{2}{l}{ Spatial correlation } \\
\cline { 2 - 3 } & Global & Land & Ocean & & Global & Land & Ocean \\
\hline IFS T159 & 1.60 & 1.40 & 1.66 & & 0.88 & 0.90 & 0.88 \\
IFS T511 & 1.81 & 1.70 & 1.84 & & 0.87 & 0.87 & 0.88 \\
IFS T1279 & 1.91 & 1.87 & 1.92 & & 0.87 & 0.85 & 0.88 \\
IFS T2047 & 1.64 & 1.65 & 1.64 & & 0.83 & 0.90 & 0.82 \\
NICAM & 2.39 & 2.59 & 2.32 & & 0.73 & 0.79 & 0.71 \\
CCSM T42 & 2.20 & 1.99 & 2.03 & & 0.72 & 0.77 & 0.73 \\
SP-CCSM & 1.76 & 1.78 & 1.75 & & 0.80 & 0.82 & 0.81 \\
\hline
\end{tabular}

Europe, eastern China and the East Asian storm track, the Ganges Delta, southern India, Indonesia and the Great Plains of North America at all resolutions. Rainfall is excessive over the western tropical and subtropical Pacific, northern Indian Ocean, and western Atlantic.

NICAM (upper right) shows a stark deficit of precipitation over the western Pacific and monsoonal Asia-an acknowledged problem with this model. There is also too little rainfall over the oceanic storm track regions. Excessive precipitation is found near the equator in the Indian Ocean, along the northern margin of the South Pacific Convergence Zone, the tropical storm regions of the eastern Pacific, and large parts of Africa, Arabia, Indonesia and the semi-arid parts of Asia and the western US.

The precipitation features of CCSM change drastically in many regions when comparing the super-parameterization with the native configuration (middle panels of the right column). Both configurations show a deficit of rainfall over tropical land regions, with excess rainfall over much of the low-latitude oceans. Over land there are many differences visible over the subtropical and mid-latitude continents.

Table 2 shows the root mean square error (RMSE) and spatial correlations of the seasonal JJA mean precipitation of each model compared to GPCP. In addition to global totals between $50^{\circ} \mathrm{N}$ and $50^{\circ} \mathrm{S}$, the statistics are calculated for ocean only and land only. Curiously, for IFS the highest RMSE over land and ocean are at the $16 \mathrm{~km}$ resolution (T1279), reflecting the strong wet bias. Over land, the smallest errors are at the lowest resolution, but over ocean they are at the highest. The reverse is true for pattern correlations, where T2047 has a spatial correlation of 0.90 over land. Over ocean, the best correlation is at T159 and the worst at T2047. NICAM has consistently higher errors and lower correlations than any IFS simulations. RMSE for CCSM tends to lie between the two other models, but improves markedly when the super-parameterization is switched on, declining by $11 \%$ over land and $14 \%$ over ocean. There are also improvements in the spatial correlations by 0.05 over land to 0.82 , and by 0.08 over ocean to 0.81 .
Table 3 shows the statistics for the amplitude of the diurnal cycle of precipitation for JJA. Comparisons are made with two different data sets, the TRMM and the CMORPH products. Recall that TRMM and CMORPH estimates of precipitation rates have been scaled before statistics are computed so that the monthly and seasonal mean precipitation agrees with GPCP. Generally speaking, the models' agreements are slightly better with CMORPH than with TRMM. RMSE and correlations improve with increasing resolution for IFS over ocean and land. NICAM performs slightly worse than IFS in the simulation of the amplitude of the diurnal cycle, but better than CCSM. The highest resolution run of IFS has the lowest RMSE and the best pattern over land and globally. There is a rather marked improvement in the RMSE in IFS as the resolution is increased from $\mathrm{T} 159$ to $\mathrm{T} 511$, and then gradual improvement as resolution is increased further. The pattern correlations also tend to increase with resolution. CCSM with its default cloud and convective parameterizations uniformly has the lowest correlations, and the worst RMSE over land. SP-CCSM shows marked improvement over CCSM-RMSE over land is nearly cut in half. Spatial correlations in the amplitude of the diurnal cycle improve by about 0.17 over land, and $0.08-0.10$ over ocean.

Figure 2 shows the global maps of the amplitude of the diurnal cycle of precipitation (scaled as described above to agree with GPCP totals) and the model errors in this quantity. Values compared to TRMM are shown, but comparisons to CMORPH are very similar. Observational data in the bottom right panel show that the amplitude of the diurnal cycle reflects the pattern of total precipitation, but is relatively suppressed over ocean. The models show a tendency for too large a diurnal cycle over tropical oceans, and over some land areas in the Northern Hemisphere. These correspond largely to areas where each model overpredicts the mean precipitation. Mexico and India are locations where the diurnal cycle amplitude is consistently under-simulated across models. Mexico is a location where errors in diurnal cycle amplitude appear to follow the mean precipitation biases, but all of the IFS simulations show 
Table 3 As in Table 2 for the amplitude of the diurnal cycle of precipitation $(\mathrm{mm} / \mathrm{d})$ during $\mathrm{JJA}$

First value is relative to TRMM second is relative to $\mathrm{CMORPH}$

\begin{tabular}{|c|c|c|c|c|c|c|}
\hline & \multicolumn{3}{|l|}{ RMSE } & \multicolumn{3}{|c|}{ Spatial correlation } \\
\hline & Global & Land & Ocean & Global & Land & Ocean \\
\hline IFS T159 & $1.17 / 1.20$ & $1.68 / 1.77$ & $0.93 / 0.92$ & $0.75 / 0.75$ & $0.76 / 0.76$ & $0.69 / 0.72$ \\
\hline IFS T511 & $0.92 / 0.89$ & $1.30 / 1.29$ & $0.75 / 0.71$ & $0.77 / 0.78$ & $0.79 / 0.79$ & $0.72 / 0.74$ \\
\hline IFS T1279 & $0.85 / 0.80$ & $1.20 / 1.12$ & $0.70 / 0.65$ & $0.77 / 0.79$ & $0.79 / 0.79$ & $0.73 / 0.76$ \\
\hline IFS T2047 & $0.82 / 0.71$ & $1.13 / 0.97$ & $0.68 / 0.59$ & $0.78 / 0.79$ & $0.80 / 0.81$ & $0.70 / 0.74$ \\
\hline NICAM & $1.15 / 1.14$ & $1.70 / 1.73$ & $0.87 / 0.84$ & $0.72 / 0.74$ & $0.72 / 0.73$ & $0.68 / 0.72$ \\
\hline CCSM T42 & $1.21 / 1.21$ & $2.03 / 2.07$ & $0.72 / 0.68$ & $0.59 / 0.57$ & $0.56 / 0.53$ & $0.58 / 0.59$ \\
\hline SP-CCSM & $0.87 / 0.82$ & $1.27 / 1.10$ & $0.68 / 0.70$ & $0.68 / 0.68$ & $0.73 / 0.71$ & $0.68 / 0.67$ \\
\hline
\end{tabular}

areas of excessive rainfall over India where nonetheless they show too weak a diurnal cycle.

Table 4 presents the statistics for the phase of the diurnal cycle, which is indicated at each point as the hour of maximum precipitation during JJA, calculated as described in Sect. 3. All land points are included in these calculations, between $50^{\circ} \mathrm{S}$ and $50^{\circ} \mathrm{N}$, but only ocean points where TRMM or CMORPH data indicate the amplitude is at least half of the mean rainfall. This tends to mask out most of the ocean points away from coastlines, except over the stratus cloud decks in the eastern midlatitude and subtropical basins. The phase error in IFS tends to improve gradually with resolution, but only up to T1279. There is a slight degradation when the resolution is increased to T2047.

Figure 3 shows the spatial distribution of the errorsregions where the observed (TRMM) magnitude of the diurnal cycle is less than half the seasonal mean rainfall rate over ocean are masked. The simulations with NICAM are superior to the other models in minimizing the phase error, although the errors are still far from small. This high skill was found by Sato et al. (2009) for the tropics in simulations at $3.5,7$ and $14 \mathrm{~km}$ resolutions. The largest errors and weakest spatial correlations are for the control simulation of CCSM. The highest correlations are shared among NICAM and IFS simulations, but there is no clear connection between resolution and skill, and in no case are correlations as high as 0.25 .

It is interesting to note the ratio of the amplitude of the diurnal cycle to the mean rainfall rate (Fig. 4). TRMM shows that precipitation synchronized to the diurnal cycle predominates over many arid and mountainous regions of the world, as well as the stratus decks of the Pacific and Atlantic, and certain coastal regions (e.g., Southeast US, the Atlantic coast of Brazil, the monsoon region of North America, Indonesia and eastern Africa). None of the models reproduce the intensity of the diurnal harmonic over the stratus decks or the mid-latitudes of the Southern Hemisphere. The models also tend to over represent the diurnal cycle over land, particularly those with parameterized convection and low resolutions (IFS T159 and
CCSM T42). Table 5 shows that NICAM tends to have the lowest global RMSE relative to either TRMM or CMORPH, so best represents the portion of total rainfall coming from the diurnal harmonic. Again, the performance of IFS globally and over land improves gradually with increasing resolution.

\subsection{Regional features}

Certain regions of the world are renowned for diurnal precipitation features, usually triggered orographically or by sea breeze circulations. For instance, over North America, there are several notable rainfall features during summer that are strongly diurnal. Figure 5 shows the phases of the diurnal cycle for each model and for TRMM for this region. The same screening criterion over oceans has been applied, except now each model's own amplitude ratio is applied, and no data is shown where the precipitation rate is less than $0.25 \mathrm{~mm} / \mathrm{d}$. Also, unlike the previous figures, the data from each model and observations are shown at their native resolutions.

The lower right panel shows the TRMM assessment of the hour of peak precipitation. Many land areas show an afternoon maximum in rainfall. However, there is a wellknown progression eastward from the front range of the Rocky Mountains toward the Mississippi River. Convective systems often form over the eastern Rockies and propagate eastward, so that there is a maximum in rainfall between midnight and sunrise stretching northeastward from eastern Oklahoma to the Great Lakes.

There are also some interesting land-sea contrasts in precipitation. Over much of the Gulf of Mexico, there is a morning maximum of rainfall. As the coastal sea-breeze intensifies with the warming of the land surface, subsidence stifles cloud formation over the Gulf, and an afternoon maximum in rainfall is seen over adjacent land areas. Along the Pacific coast of Mexico, there is a nighttime rainfall maximum off the coast as part of the regional sea breeze component of the North American monsoon. Inland, there are complex propagations of rainfall as documented by Gochis et al. (2004). 
Fig. 2 As in Fig. 1 for the amplitude of the diurnal cycle ( $\mathrm{mm} / \mathrm{d}$ ) compared to TRMM where the TRMM precipitation rate has been scaled so the seasonal mean precipitation agrees with GPCP
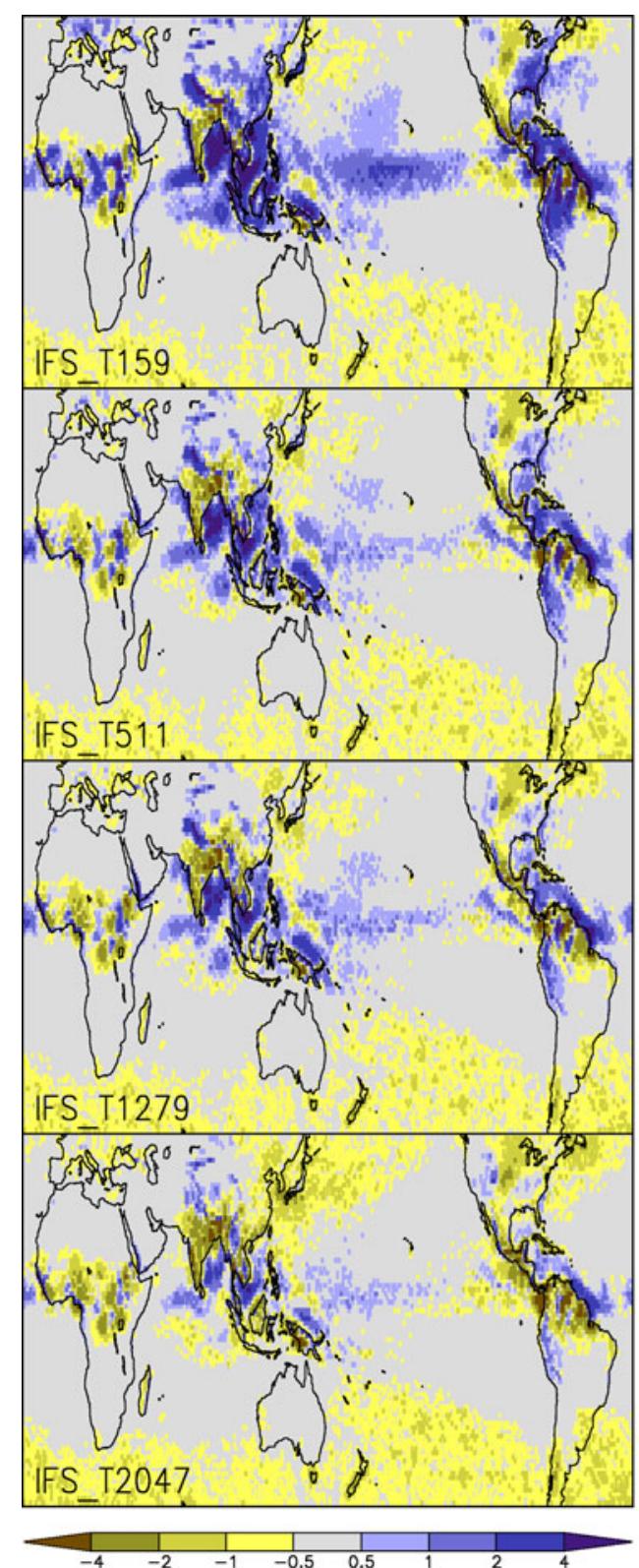
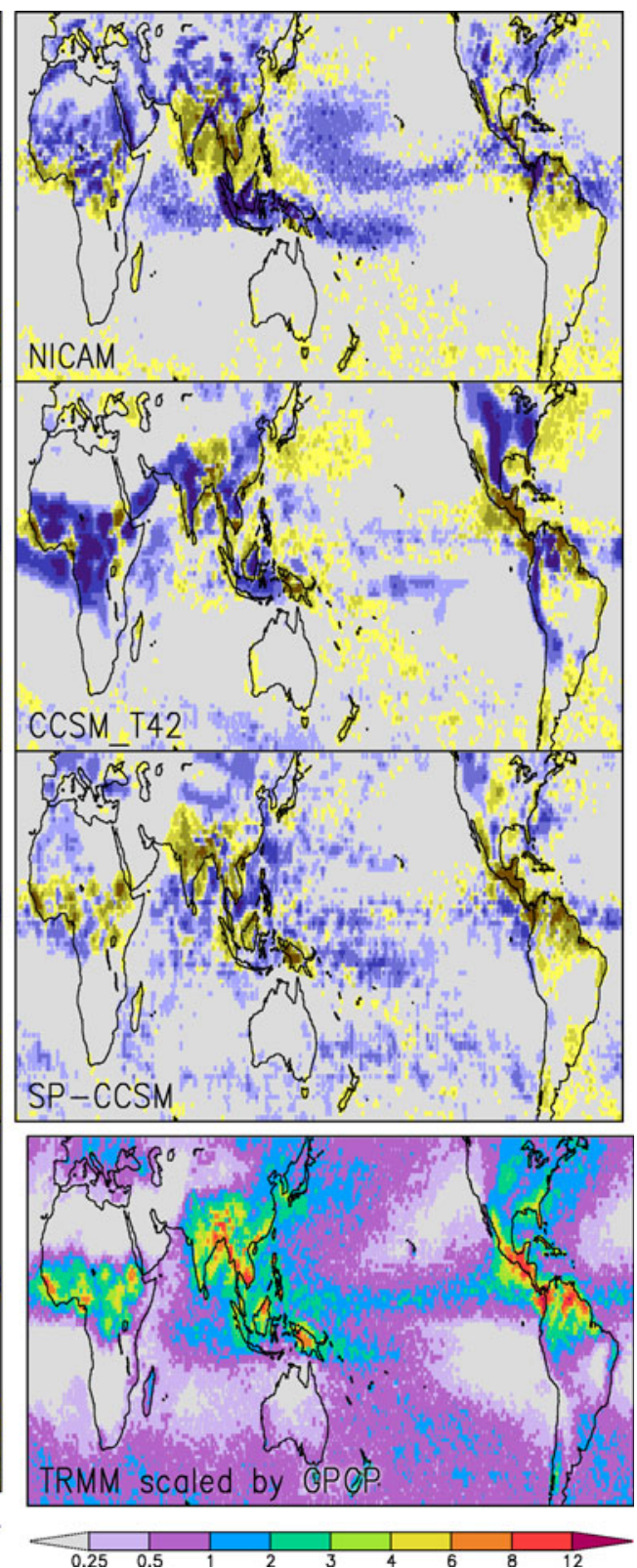

Table 4 As in Table 3 for the phase of the diurnal cycle of precipitation (hours) during JJA

\begin{tabular}{|c|c|c|c|c|c|c|}
\hline & \multicolumn{3}{|l|}{ RMSE } & \multicolumn{3}{|c|}{ Spatial correlation } \\
\hline & Global & Land & Ocean & Global & Land & Ocean \\
\hline IFS T159 & $7.1 / 6.2$ & $8.0 / 6.7$ & $5.2 / 5.0$ & $0.20 / 0.23$ & $0.17 / 0.14$ & $0.03 / 0.06$ \\
\hline IFS T511 & $6.8 / 6.0$ & $7.6 / 6.5$ & $5.2 / 5.0$ & $0.22 / 0.24$ & $0.18 / 0.13$ & $0.03 / 0.06$ \\
\hline IFS T1279 & $6.7 / 5.9$ & $7.5 / 6.4$ & $5.1 / 5.0$ & $0.21 / 0.24$ & $0.17 / 0.15$ & $0.02 / 0.05$ \\
\hline IFS T2047 & $6.8 / 6.0$ & $7.5 / 6.3$ & $5.4 / 5.2$ & $0.24 / 0.26$ & $0.17 / 0.16$ & $0.02 / 0.04$ \\
\hline NICAM & $5.0 / 5.0$ & $5.0 / 5.1$ & $5.0 / 4.7$ & $0.21 / 0.23$ & $0.12 / 0.10$ & $0.05 / 0.07$ \\
\hline CCSM T42 & $7.4 / 6.8$ & $8.1 / 7.3$ & $6.1 / 5.8$ & $-0.10 /-0.10$ & $0.07 / 0.05$ & $-0.04 /-0.02$ \\
\hline SP-CCSM & $6.7 / 6.1$ & $7.2 / 6.4$ & $5.8 / 5.5$ & $-0.02 / 0.00$ & $0.04 / 0.08$ & $-0.01 / 0.01$ \\
\hline
\end{tabular}

There is great diversity in the behavior of the models. IFS and CCSM show a propensity to produce maximum rainfall around local noon, like most GCMs with parameterized convection. There is an interesting feature in the higher resolution versions of IFS (T511, T1279 and T2047) over the northern Great Plains of the US that 
Fig. 3 As in Fig. 1 for the phase of the diurnal cycle of precipitation during JJA, defined as the local hour of maximum rainfall in the first daily harmonic. Units are hours
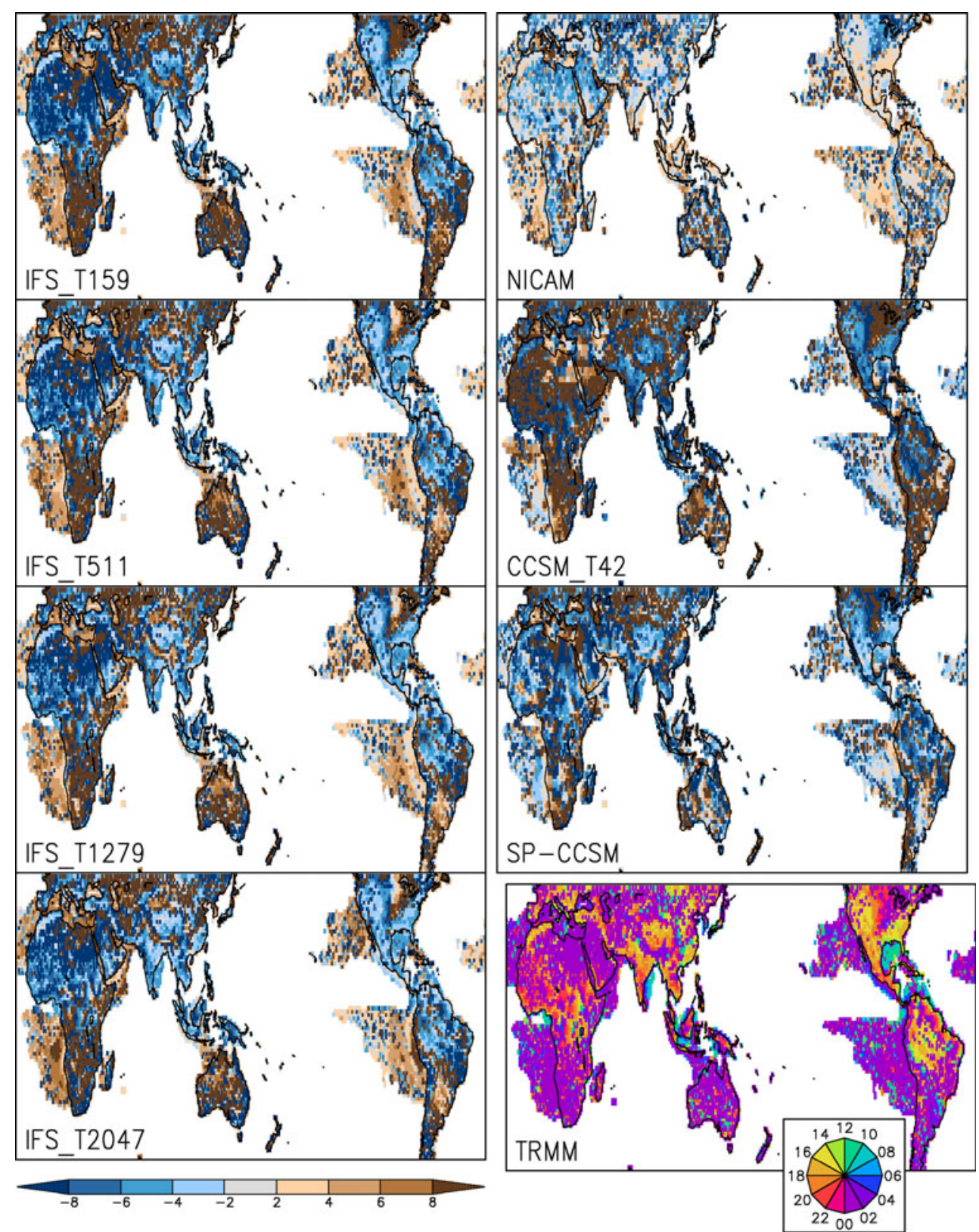

resembles the eastward propagation of a nighttime precipitation maximum. However, examination of time series (not shown) indicates this to be a very weak sporadic feature (cf. Fig. 6) that seems to be associated mainly with the presence of the Great Lakes. Otherwise, the only locations over land where convection is significantly delayed past midday are over some mountains of the central Rockies and central Mexico. Coastal oceans show a maximum near sunrise. Super-parameterization introduces changes in the timing of convection over many locations, including a hint of an eastward propagating feature near the Great Lakes. However, the Gulf Coast and much of the western US retain a noontime maximum. NICAM, with its explicit cloud simulation, exhibits delayed convection over nearly all land locations. In fact, most continental grid points have a maximum after sunset. There is also a great deal of small-scale structure that is probably a result of the limited number of years in the sample and not significant. NICAM is the only model to represent well the phasing of rainfall in the North American Monsoon region, although the pattern seems to be delayed by a couple of hours compared to TRMM. The morning maximum of rainfall over the Gulf of Mexico is also well represented in NICAM, but NICAM shows almost no trace of the propagating convection over the Great Plains.

Figure 6 shows the amplitude of the diurnal cycle during JJA for the North American region. As in the previous comparisons, the amplitude for TRMM has been scaled by 
Fig. 4 As in Fig. 1 for the ratio of the amplitude of the diurnal cycle to the mean rainfall rate
Table 5 As in Table 3 for the ratio of the amplitude of the diurnal cycle of precipitation during JJA to the mean rainfall rate
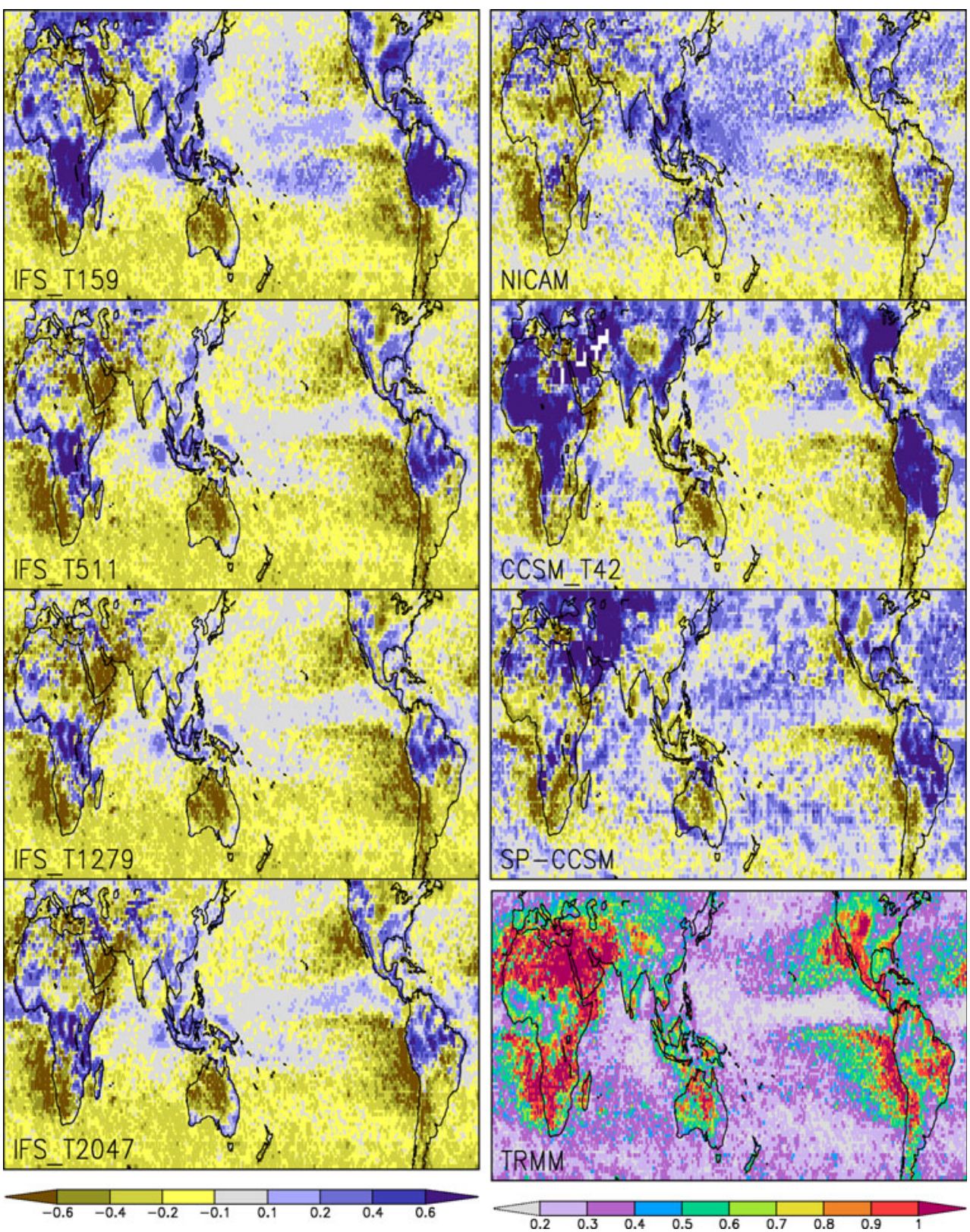

\begin{tabular}{|c|c|c|c|c|c|c|}
\hline & \multicolumn{3}{|l|}{ RMSE } & \multicolumn{3}{|c|}{ Spatial correlation } \\
\hline & Global & Land & Ocean & Global & Land & Ocean \\
\hline IFS T159 & $0.26 / 0.24$ & $0.35 / 0.36$ & $0.21 / 0.18$ & $0.62 / 0.63$ & $0.35 / 0.39$ & $0.58 / 0.64$ \\
\hline IFS T511 & $0.27 / 0.23$ & $0.34 / 0.31$ & $0.23 / 0.20$ & $0.63 / 0.63$ & $0.40 / 0.45$ & $0.59 / 0.63$ \\
\hline IFS T1279 & $0.27 / 0.23$ & $0.35 / 0.30$ & $0.23 / 0.20$ & $0.63 / 0.64$ & $0.42 / 0.47$ & $0.60 / 0.64$ \\
\hline IFS T2047 & $0.26 / 0.22$ & $0.32 / 0.29$ & $0.23 / 0.20$ & $0.63 / 0.64$ & $0.44 / 0.51$ & $0.55 / 0.59$ \\
\hline NICAM & $0.23 / 0.22$ & $0.29 / 0.28$ & $0.21 / 0.19$ & $0.61 / 0.61$ & $0.50 / 0.49$ & $0.47 / 0.51$ \\
\hline CCSM T42 & $0.27 / 0.27$ & $0.38 / 0.40$ & $0.21 / 0.19$ & $0.57 / 0.54$ & $0.31 / 0.32$ & $0.51 / 0.48$ \\
\hline SP-CCSM & $0.24 / 0.24$ & $0.32 / 0.33$ & $0.21 / 0.20$ & $0.59 / 0.55$ & $0.45 / 0.42$ & $0.49 / 0.47$ \\
\hline
\end{tabular}


Fig. 5 The local hour of maximum precipitation during JJA for the models and TRMM over a portion of North America. Ocean regions are masked if the amplitude of the diurnal cycle is less than half of the mean rainfall rate for that location, and all regions are masked if the mean precipitation rate is less than $0.25 \mathrm{~mm} / \mathrm{d}$

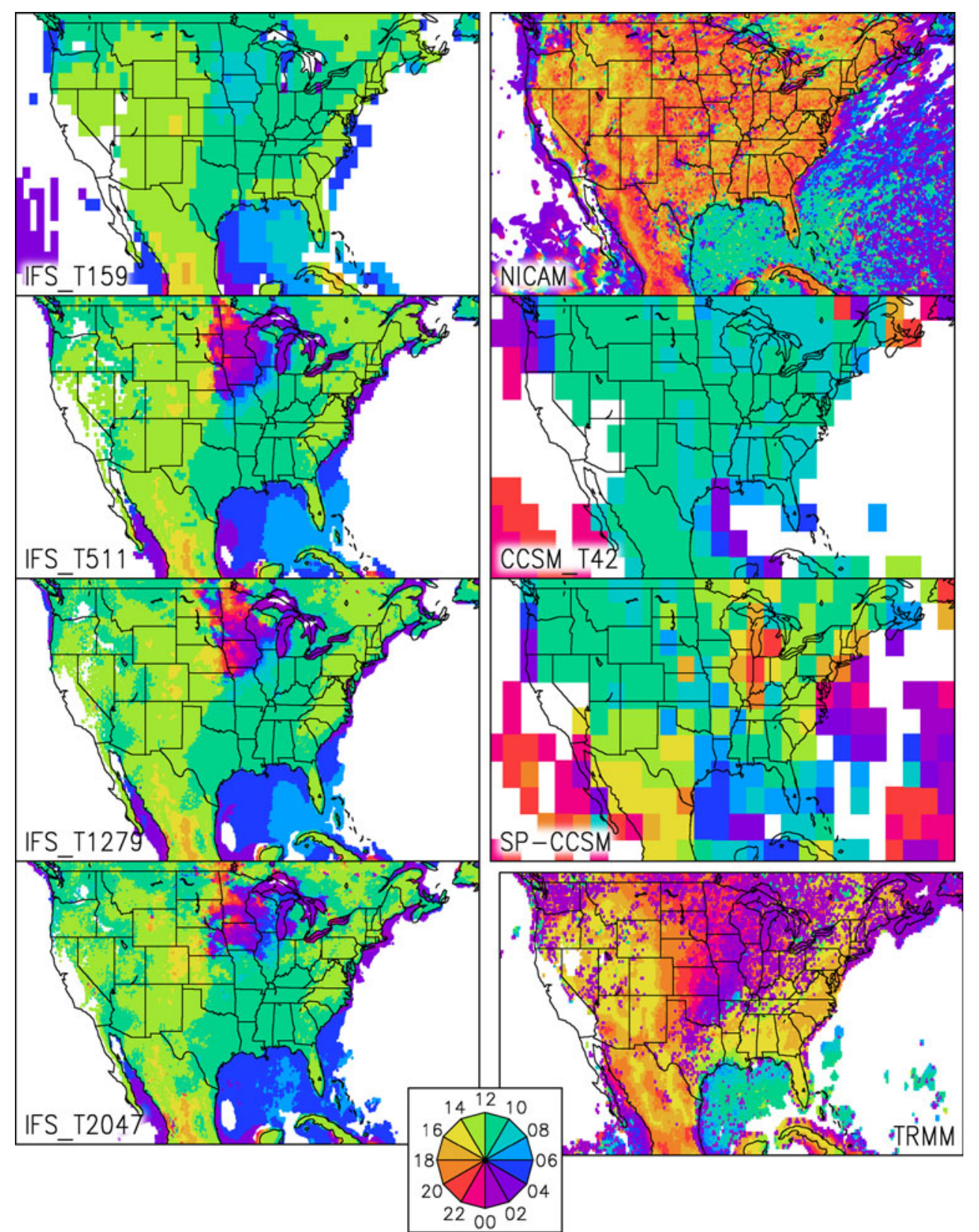

the ratio of GPCP mean precipitation (interpolated to the TRMM data grid) to the TRMM mean precipitation. Interesting structure is evident in the TRMM data. There is a broad region with a strong diurnal cycle across the Southeast US, with a maximum over Florida, and high values over Cuba (and other Caribbean islands not shown) and Yucatan. There is a band of maximum amplitude along the Sierra Madre Occidental associated with the North American monsoon. A slightly weaker but prominent area of high amplitude exists over the central Great Plains, associated with the eastward propagating convection described earlier. Between this feature and the maximum over the Southeast is a band of minimum amplitude for the diurnal cycle, extending from Texas to Ontario. The magnitude of the diurnal cycle over water is generally suppressed, except in the northern Gulf of Mexico, off the Carolina coast and off the coast of Nayarit in west-central Mexico.

Looking first at the IFS results, we find that this model captures the maximum over the Southeast quite well at all resolutions, if too strongly at T159. The best simulation appears to be at $\mathrm{T} 1279$ resolution, which also captures well the oceanic diurnal features over the northern Gulf of Mexico and off the Carolinas. The maximum over western Mexico is too strong at all resolutions of IFS, and the Great Plains is actually a minimum rather than a maximum in the 
Fig. 6 As in Fig. 5 for the amplitude of the diurnal cycle $(\mathrm{mm} / \mathrm{d})$

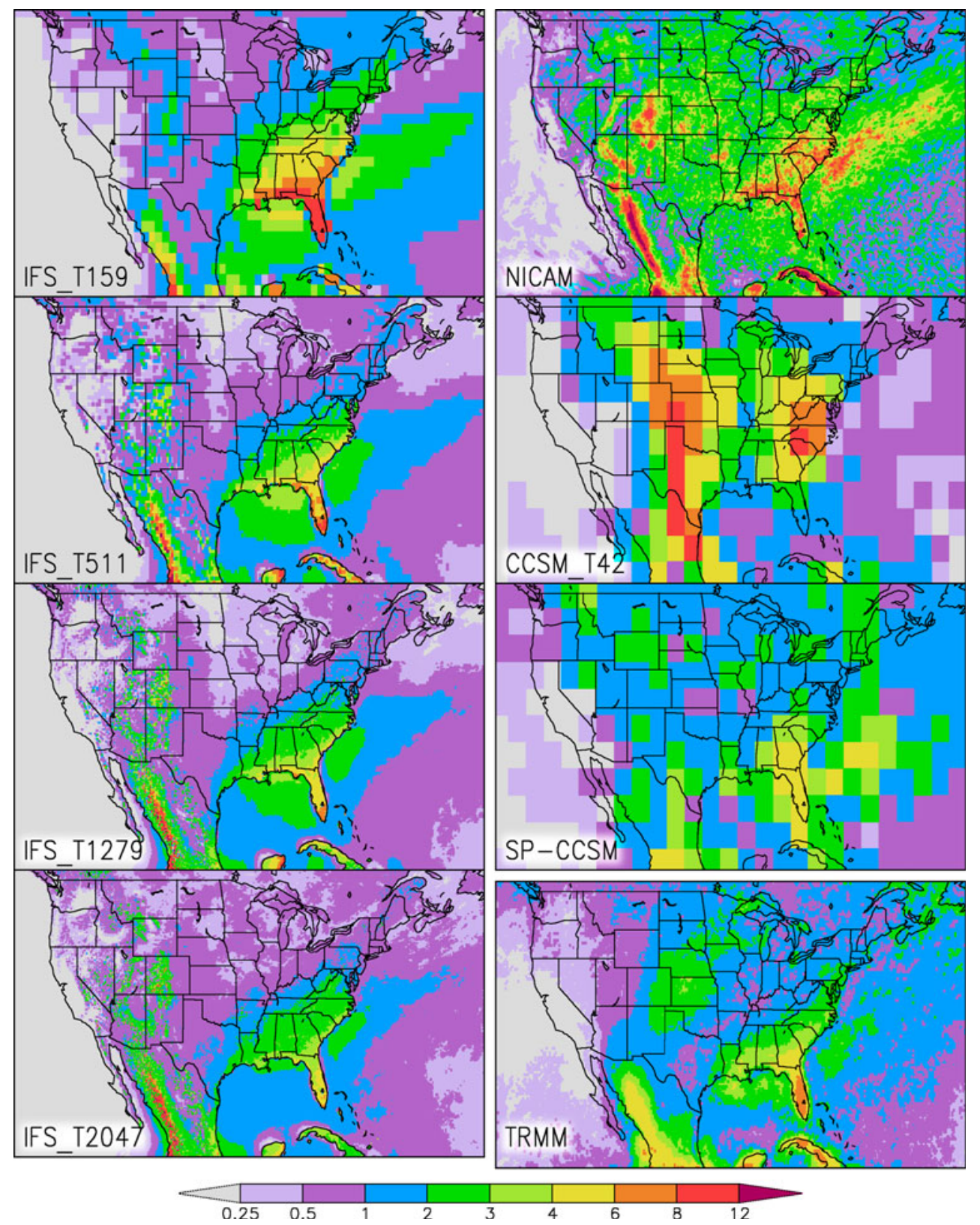

amplitude of the diurnal cycle. Instead, peaks are found over the mountains of the western US. This is also true of NICAM, which shows much stronger amplitudes than TRMM almost everywhere. There is little suggestion of a Great Plains maximum or a band of minimum amplitude over the central US. CCSM bears little resemblance to observations on a regional scale, but SP-CCSM, despite its very low resolution, picks up many of the features found in TRMM. There is no coherent Great Plains maximum, however, and the poorly resolved topography causes the maximum in rainfall over Mexico to be shifted considerably to the east.

Another region with several interesting features of diurnal precipitation patterns spans South and East Asia.
Figure 7 shows the diurnal phase over this region. Again, many regions have an afternoon peak in rainfall, according to the observed TRMM precipitation data. We focus on three features: the propagation of convection from the southern edge of the Himalayas southward over the Gangetic Plain, an eastward propagating band of convection crossing Sichuan Province, and the contrast between land and sea convection between India and the Bay of Bengal. Both the Ganges and Sichuan convective features are triggered at edges of the Tibetan Plateau with a late afternoon maximum of precipitation, and propagate afield to a sunrise maximum before the signal is lost. Along the east coast of India, there is an early afternoon maximum along Andhra Pradesh and Orissa states, but in the late 
afternoon and evening further south along the Southeastern or Tamil Nadu coast. Near shore the rainfall maximum occurs near sunrise or, further offshore, later in the morning.

It is evident at a glance that NICAM captures many of the details in the timing of precipitation over Asia. The propagation of rainfall over the Gangetic Plain is well simulated, although it appears to be confined to too narrow a band in meridional extent. The propagation over Sichuan is also present in NICAM, but again limited in spatial extent and seems to dissipate around midnight. The convective features along the eastern coastline of India, however, are duplicated with remarkable fidelity. One problem with NICAM, however, is a tendency for strong diurnal cycles over open ocean.

The performance of the other models in simulating the timing of rainfall in this region does not approach that of NICAM. Most regions in the IFS and CCSM runs have a late morning or early afternoon maximum in precipitation. SP-CCSM does appear to include more of the delayed and propagating rainfall features, but the low spatial resolution of the model's native grid makes it difficult to compare with TRMM. As over North America, the T159 simulation of IFS is quite featureless, while the higher resolutions show more structure but are quite similar to one another.

The amplitude of the mean JJA diurnal cycle of precipitation is shown in Fig. 8. TRMM/GPCP suggests a rich structure to this quantity with maxima over mountainous regions except the interior of the Tibetan Plateau and Central Asia, a chain of locations stretching from Assam and Bangladesh across Southeast Asia, northern Borneo, the major islands of the Philippines, and along the southern coast of China. There are also regions of moderately high amplitudes over ocean around the edges of the Bay of Bengal.

One could argue that CCSM outperforms the T159 version of IFS in this metric. The IFS exhibits large areas of high amplitudes over the Bay of Bengal, South China Sea, and Gulf of Thailand that are not present in observations. These errors are far larger in the T159 simulation of IFS than the others. SP-CCSM improves upon CCSM by reducing the peak amplitudes and removing the maximum over central India. While NICAM performed best in simulating the diurnal timing of rainfall, the amplitude of the diurnal cycle is much too strong in most locations, and the pattern bears only a weak resemblance to the TRMM data.

To attempt to understand the processes that underlie these differing behaviors, we examine in more detail the simulation of the diurnal cycle of rainfall over the Great Plains. Figure 9 depicts the mean diurnal cycle of summer precipitation and vertically integrated moisture transport over the Great Plains and surrounding environs. Data are shown for 6-h synoptic intervals as local time varies across the domain. Values are deviations from the grand JJA mean, such that at any location the mean across the four panels is zero. We show only three of the models, plus the GPCP-scaled rainfall data from TRMM and the MERRA reanalysis as observations. For IFS, only the T1279 run is shown, but the other resolutions show largely the same features. Also, we do not show the control CCSM simulation, which has virtually no diurnal cycle in moisture transport and a peak in terrestrial rainfall at local noon.

Looking first at TRMM/GPCP, we see a complex diurnal cycle of rainfall. Over most land areas, there are reduced rainfall rates in the 6 -h leading up to $18 \mathrm{Z}$, roughly corresponding to the period between sunrise and noon. This is a period of maximum rainfall over most of the Gulf of Mexico and the Atlantic off the coast of Florida and the Carolinas. During the afternoon (00Z), a maximum forms over the Rocky Mountains as well as much of the eastern and southern US, and Mexico. At this same time, rainfall rates are still below the mean over the central and northern Great Plains as well as coastal oceans. By the period ending at 06Z, the convection that was centered over Colorado has moved eastward, generating a maximum over the western Great Plains. Rainfall rates also remain high over Mexico, but have abated elsewhere. By the hours after midnight (12Z), the terrestrial maximum has moved to the eastern Great Plains and western Great Lakes. The vectors, indicating the advection of moisture, show a peak at $06 \mathrm{Z}$ in the Low Level Jet (LLJ) bringing moisture northward into the Great Plains from the Gulf of Mexico. At 12Z, the feature has weakened and advection anomalies become more eastward trailing the propagating peak in precipitation.

IFS, NICAM and SP-CCSM all capture the timing and gross shape of the LLJ and other circulation features at 06Z, and the eastward turning at 12Z. They also do a fair job of capturing the other half of the oscillation at $18 \mathrm{Z}$ and 00Z. Yet the simulations of the daily cycle of rainfall lack many key features found in the observations. At 00Z, NICAM looks reasonably good, except it lacks the relatively low rainfall rates over the central and northern Great Plains. This is seen in later panels to be due to the lack of the eastward-propagating convective feature in the model. Leading up to 06Z, NICAM persists convective rainfall too much over eastern US and mountain west. The $12 \mathrm{Z}$ maximum in precipitation over the plains is absent. SP-CCSM has a $12 \mathrm{Z}$ maximum, but displaced to the southern Mississippi basin and northeastern Gulf of Mexico. It has a very narrow LLJ at 06Z, and a poorly simulated rainfall maximum over the Great Plains at this time. It is quite possible that the low resolution of this model hampers its ability to simulate these features. The dipoles between land and ocean are not well represented in SP-CCSM. However, there is evidence that the midday rainfall maximum 
Fig. 7 As in Fig. 5 for South and East Asia

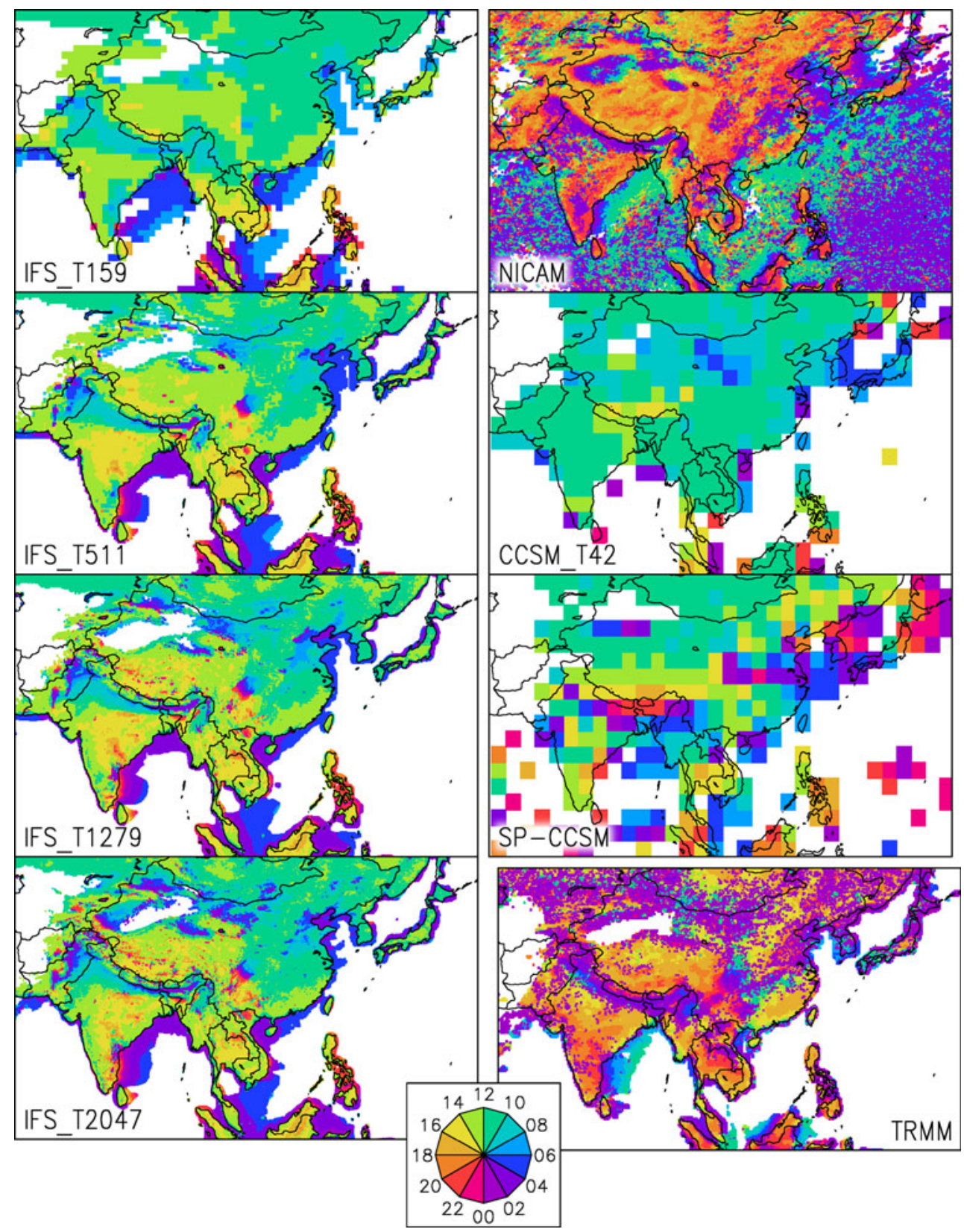

endemic of models with parameterized convection exists even in this model over the Southeast US.

The 00Z frame for IFS looks quite good when compared to TRMM/GPCP. However, we see, at $06 \mathrm{Z}$ and 12Z, that the propagating rainfall over the Great Plains is absent. What appears in Fig. 5 to be a promising phasing of rainfall over the northern Great Plains in IFS is found to be not a propagating feature, but a stationary one just east of the Great Lakes. It is present at all resolutions of IFS (not shown). This model also simulates the maritime rainfall maximum over the Gulf of Mexico and Atlantic several hours too early, and like SP-CCSM, triggers convection over the Southeast US during the morning.
The mean northward transport of moisture and the magnitude of the diurnal cycle of this transport are also simulated similarly and accurately by most of the models (Fig. 10). Transport at $35^{\circ} \mathrm{N}$ is shown. CCSM and SPCCSM are somewhat weak in both of these terms, but IFS and NICAM appear to simulate the LLJ well. There is remarkably little variation across the wide range of resolutions for IFS.

From these results, we cannot explain the errors and inter-model variability by the dynamics of the models. With the exception of CCSM, all the GCMs produce similar moisture transport and reasonable low level jet position, magnitude and variability. Thus, the difference 
Fig. 8 As in Fig. 6 for South and East Asia

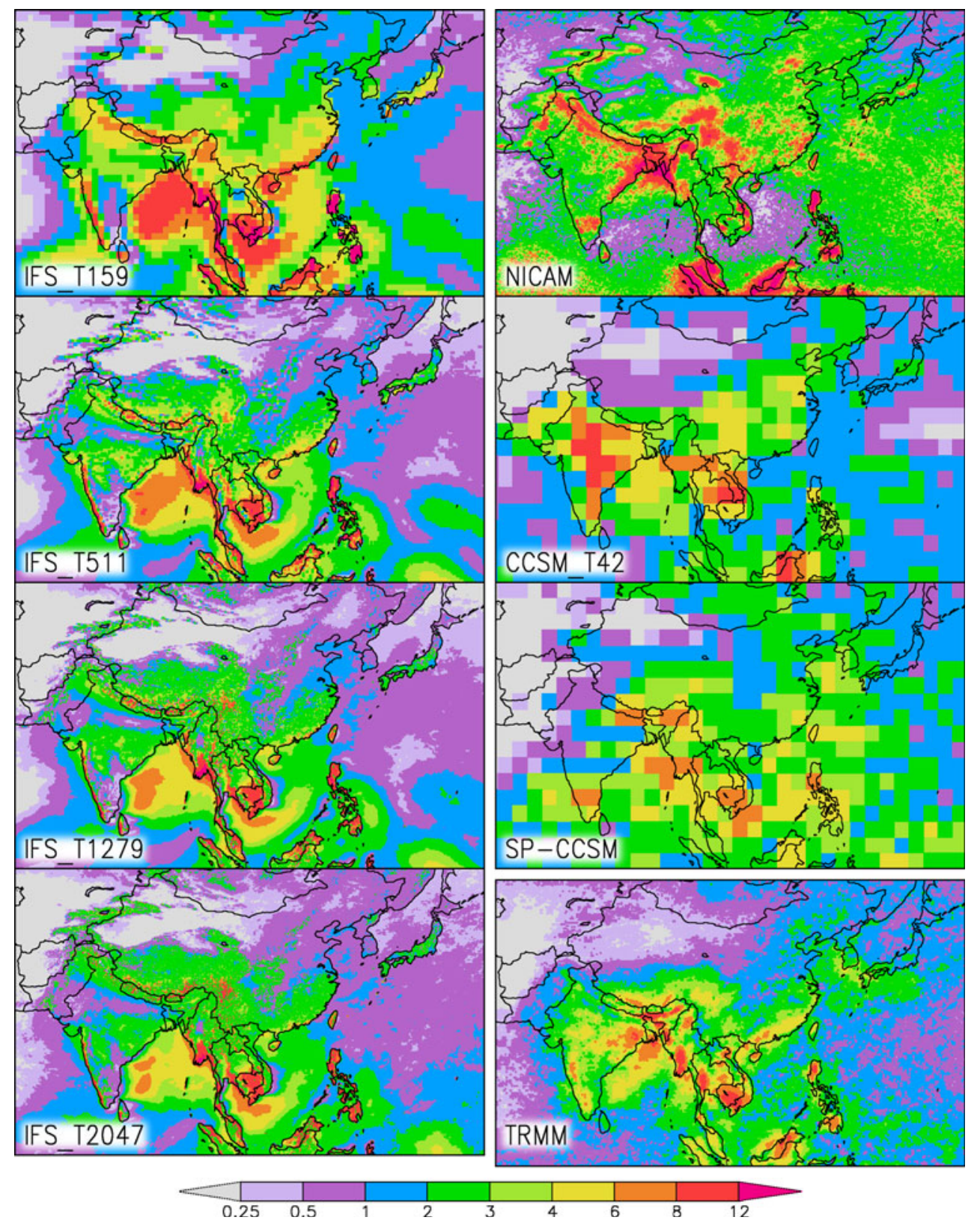

must result from the behavior of the "physics" in the models-parameterizations of convection, clouds and the boundary layer, or in the case of SP-CCSM, the superparameterization of clouds and convection. Comparison of the diurnal cycle of total cloud cover to results of Wylie (2008) and Stubenrauch et al. (2006) (not shown) indicates SP-CCSM to have quite good phasing in this region, much improved over CCSM. IFS also compares well, with little sensitivity to resolution, despite its problems in precipitation simulation. NICAM has a very weak diurnal cycle of cloudiness in most locations, in contrast to its strong diurnal cycle in precipitation. Thus, it is hard to find a robust connection between skill in the diurnal cycles of cloud cover and precipitation.

\section{Conclusions}

The failings of standard GCMs with bulk convective parameterizations have been well documented-convection generally peaks when net radiative energy peaks, near local noon. Many of the models' precipitation characteristics are not typically observed in nature. We have presented an analysis of the ability of several innovative weather and climate models to simulate key aspects of the diurnal cycle of precipitation during boreal summer. We have examined several novel model simulations: seasonlong integrations of a global atmospheric model with an explicit representation of clouds and convection (NICAM), yearly integrations of the operational ECMWF forecast 

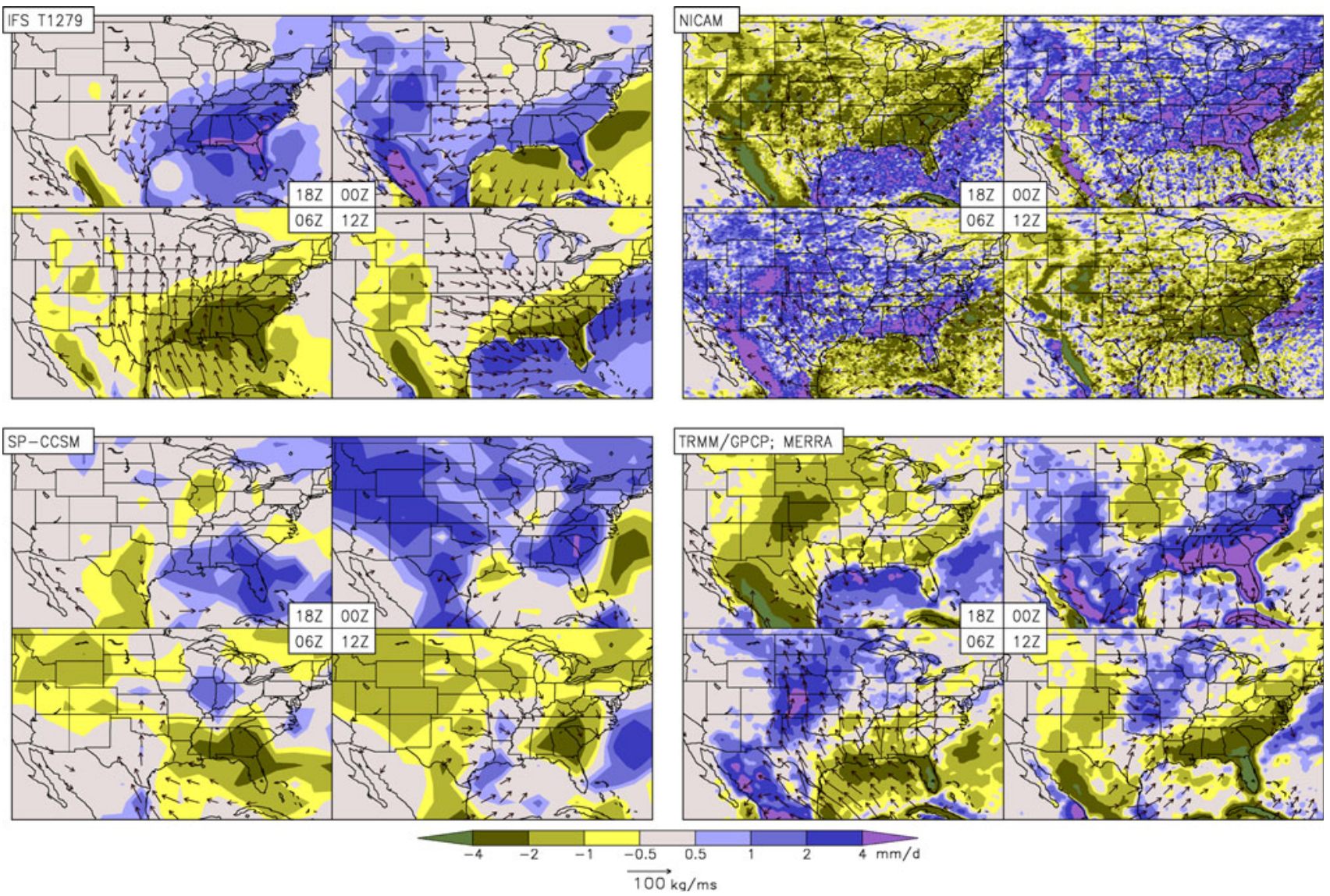

Fig. 9 6-h mean perturbations from the overall JJA mean of precipitation (shading; period ending at indicated time) and instantaneous vertically integrated moisture transport (vectors values under

model (IFS) at three resolutions, seasonal simulations of IFS at an unprecedented $10 \mathrm{~km}$ resolution, and seasonal simulations of CCSM with and without an embedded two-dimensional super-parameterization of convection (SP-CCSM). These are compared to satellite-based observations of the diurnal cycle of precipitation (TRMM, CMORPH) whose magnitudes have been scaled to match monthly observations (GPCP).

Resolution appears to have very little impact on the ability of IFS to simulate the diurnal cycle. Although there is generally improvement as horizontal resolution is increased from 125 to 39,16 and $10 \mathrm{~km}$, the improvements are increasingly gradual. Improved accuracy in describing features of the topography seems to have little bearing on the timing of rainfall in most locations, especially above the lowest resolution utilized. Improvements in the amplitude of the diurnal cycle occur, but they appear to come via improvements in the mean rainfall rate with increasing resolution, and not by meaningful changes in the diurnal cycle itself.

The introduction of the two-dimensional (zonal-vertical) super-parameterization of clouds and convection into a very low-resolution configuration of CCSM caused a
$20 \mathrm{~kg} \mathrm{~m}^{-1} \mathrm{~s}^{-1}$ masked) for IFS T1279, SP-CCSM, NICAM and observations (scaled TRMM precipitation and MERRA moisture advection)

substantial improvement in the seasonal mean and diurnal cycle of precipitation. Tao et al. (2009) found similar improvements in the character of the diurnal cycle with cloud super-parameterizations installed in an older version of the Community Climate Model (not coupled to an ocean model) and the Finite Volume GCM of NASA-Goddard, run at similar resolutions to SP-CCSM here, are found.

Improvement in SP-CCSM is not found in all locations, and may be related to the orientation of the two-dimensional grid within the GCM grid cells. It may be that orienting the cloud-resolving model parallel to the prevailing wind, as opposed to always orienting it zonally, would improve the results further. Also, the periodic lateral boundary conditions in the super-parameterization may have negative consequences for the simulation of propagating convective systems.

The NICAM model with explicit convection, even though the grid scale is too large $(7 \mathrm{~km})$ to realistically resolve cloud processes, captures features that the IFS model with parameterized convection at a similar resolution cannot. This is consistent with findings from regional models (e.g., Clark et al. 2007). The peak hour of rainfall in NICAM is delayed 
Fig. 10 Mean meridional water vapor transport (contours $\mathrm{g} \mathrm{m} \mathrm{kg}^{-1} \mathrm{~s}^{-1}$ ) across $35^{\circ} \mathrm{N}$, and the magnitude of the diurnal cycle of meridional water vapor transport (shading). Vertical coordinate is atmospheric pressure $(\mathrm{hPa})$

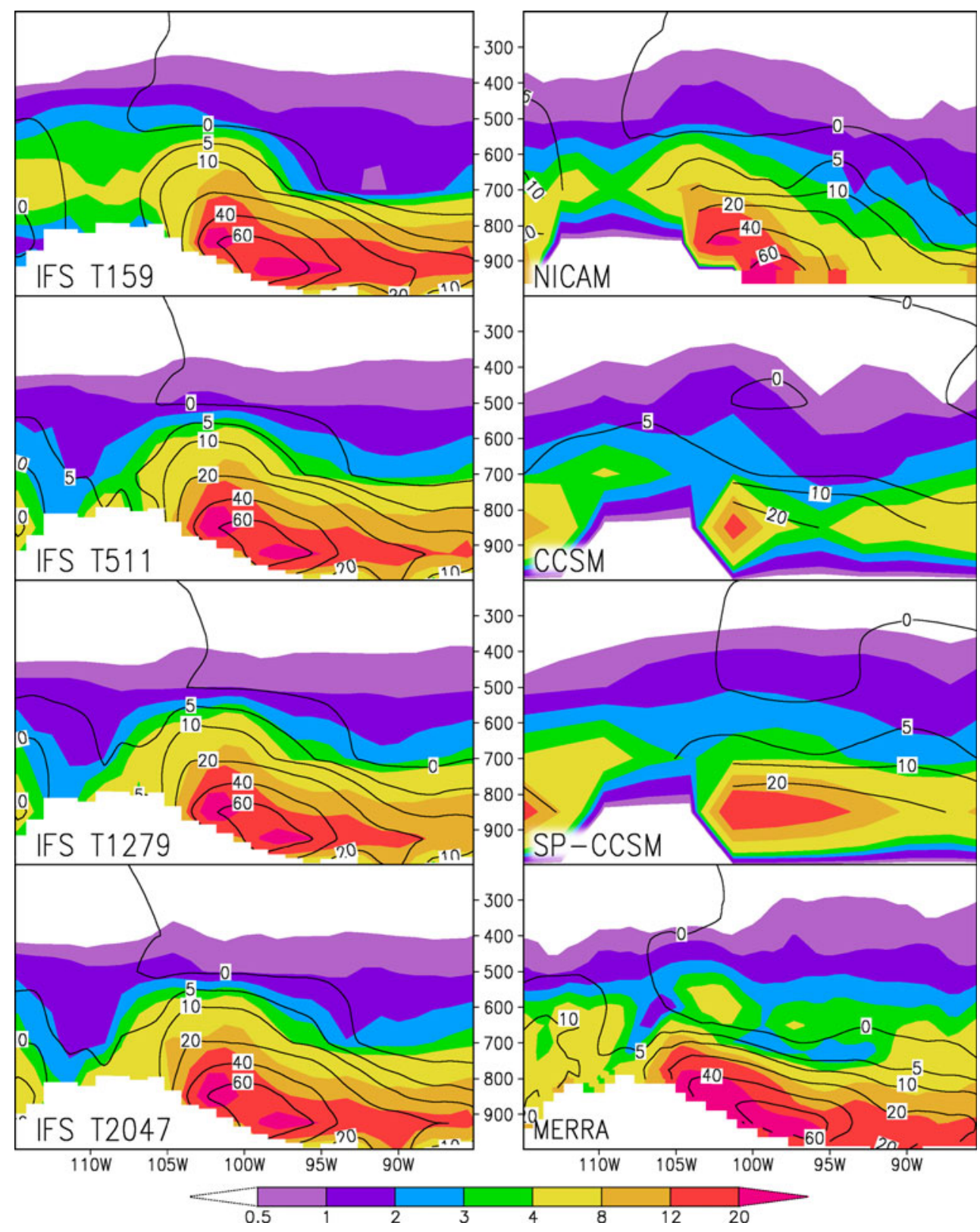

until afternoon or evening in most locations, similar to observations. Many places that have topographically triggered propagating lines of convective storms are reflected in the precipitation statistics of NICAM. Sato et al. (2009) note from shorter integrations that NICAM at $3.5 \mathrm{~km}$ resolution agrees even better with observations.

Within these general conclusions, we do find that there are regional features that are well simulated by the models with parameterized clouds and convection. Likewise, some regional features still escape the models with a more explicit approach to the simulation of rainfall. Of particular interest is the inability of any of the models to properly simulate the convective systems that frequently develop over the Front Range of the Rocky Mountains and propagate for hours eastward over the Great Plains (Riley et al. 1987). Zhang (2003) was able to improve the diurnal cycle of convection in an older version of the NCAR model by modifying the convective parameterization to be based on the tropospheric large-scale forcing instead of local convective available potential energy. That result suggests that hope remains for simulating convection with parameterizations. For instance, one possible adjustment to the convective super-parameterization could be to orient the 2-D cloud scheme with the prevailing flow instead of always zonally. SP-CCSM appeared to struggle where the prevailing low-level flow is meridional, such as over the U.S. Great Plains. It should be noted that no tuning was performed on any of these models to address the diurnal 
cycle, nor to address any errors that might arise in running these models for extended durations at high resolutions. This is particularly true for the IFS simulations at T2047, and this may explain some of the anomalous behavior of this previously untested resolution when comparing the lower resolutions of IFS. That said, it appears that there is little to be gained in the simulation of the phasing of rainfall during the day by merely increasing model resolution when convection remains parameterized.

Many large eddy simulations and sub-kilometer limitedarea modeling studies suggest that only at much higher resolutions than those examined here can the diurnal cycle reliably be modeled well. It is beyond the scope of this paper to determine if parameterizations can be designed to overcome these difficulties. However, if convective parameterizations could better capture the statistical effect of the entire convective life-cycle (in particular the sub-grid effect of sloping terrain, differential heating due to radiation on slopes, variation of surface parameters, etc.) and its interaction with the large-scale (Zhang 2003), inexpensive improvement may yet be possible. As this study shows, neither partly-resolved nor existing parameterizations in global models capture all features of the diurnal cycle of precipitation. None of these models represents the abovementioned surface-boundary layer interactions. We did not investigate here the possible role of the land surface models, or coupled land-atmosphere interactions in the timing of local rainfall. If the daily cycle of surface fluxes and growth of the planetary boundary layer are poorly represented, there is little hope that convective rainfall will trigger at the right time. Results with SP-CCSM versus CCSM suggest that the land surface models likely cannot be held culpable for all the errors found here. There are also many other differences among models in addition to those highlighted in this study that may contribute to the differences found. For instance, the IFS cloud scheme only has three species; cloud liquid water, cloud ice and cloud fraction, versus the 6-category scheme used in NICAM. Nonetheless, it is the nature of parameterized bulk convective schemes to be highly dependent on atmospheric stability for triggering, and changes in stability are locked to local noon in these models.

Acknowledgments The results described herein were obtained in the 2009-2010 Athena Project, a computationally intensive project that was carried out using the Athena supercomputer at the National Institute for Computational Sciences (NICS), under the auspices of the National Science Foundation (NSF). Support provided by NICS and the NSF (grants 0830068 and 0957884 ) is gratefully acknowledged. We also acknowledge the support of the European Centre for Medium-range Weather Forecasts (ECMWF), which provided the IFS code, boundary and initial conditions data sets, and run scripts, and the Japan Agency for Marine-Earth Science and Technology (JAMSTEC) and the University of Tokyo, which provided the NICAM code and essential data sets as well as assistance with the conversion and running of the code on Athena.
Open Access This article is distributed under the terms of the Creative Commons Attribution Noncommercial License which permits any noncommercial use, distribution, and reproduction in any medium, provided the original author(s) and source are credited.

\section{Appendix: Estimating the diurnal cycle}

Output data from the models and the high time-resolution observationally-based data are available at various sub-diurnal time intervals, ranging from hourly to 3- and 6-hourly. Here, we describe the methods used to estimate the phase and magnitude of the diurnal cycle from data at different time resolutions. In each case, the average diurnal cycle for a month or season is calculated over all relevant days $\left(d=1 \ldots d_{T}\right)$ and years $\left(y=1 \ldots y_{T}\right)$ for each interval $i$ in the diurnal cycle:

$p_{i}=\frac{1}{y_{T} d_{T}} \sum_{y=1}^{y_{T}} \sum_{d=1}^{d_{T}} p_{i, d, y}$

Phase is defined as the hour of peak rainfall in the mean diurnal cycle. For the hourly NICAM output, the hour of the peak mean precipitation among the 24 hourly steps represents the phase, and the amplitude is half the difference of maximum and minimum mean precipitation rates during the day.

For IFS, a diurnal cycle represented as a simple sine wave is optimally fitted to the four points in time representing monthly-mean precipitation during the 24-h period, and the phase and amplitude are calculated based on that harmonic. This helps to account for the marginal sampling of a sine wave with only four points across an interval of $2 \pi$-the minimum sampling which can resolve the diurnal harmonic. Given four values for precipitation $\left(p_{1}, p_{2}, p_{3}\right.$, $p_{4}$ ) at 6-hourly intervals, the hour of peak precipitation is estimated as a fit to the first harmonic via

$\frac{12}{\pi} \tan ^{-1}\left(\frac{p_{4}-p_{2}}{p_{3}-p_{1}}\right)+\frac{\lambda}{15}-\phi$,

where $\lambda$ is the longitude east from the prime meridian and $\phi$ is a phase adjustment based on the difference of the hour of $p_{1}$ relative to 0000 UTC (all observed and model data sets are registered by UTC rather than local time). When there are four points representing the diurnal cycle, the magnitude of the diurnal harmonic is the equivalent of the root mean square difference from the mean:

$\sqrt{\frac{1}{n} \sum_{i=1}^{n}\left(p_{i}-\bar{p}\right)^{2}}$

where $n=4$ and

$\bar{p}=\frac{1}{n} \sum_{i=1}^{n} p_{i}$ 
In the data sets where precipitation is reported at 3-hourly intervals, which include CCSM, SP-CCSM, TRMM and $\mathrm{CMORPH}$, at each grid point the maximum value of precipitation $p_{\max }$ is determined at time interval $i=i_{\max }$ after a centered 3-point average has been applied to filter out higher frequency variations. The adjacent time steps $i_{\max }-1$ and $i_{\max }+1$ are checked to ensure one contains the second greatest value of precipitation $p_{\mathrm{m} 2}$. If this is the case, the hour of maximum rainfall is then shifted from the time of $p_{\max }$ toward the time of second greatest precipitation $p_{\mathrm{m} 2}$ by the offset:

$3 \max \left\lfloor\frac{\left(p_{m 2}-\bar{p}\right)^{2}}{\left(p_{\max }-\bar{p}\right)^{2}}-0.5,0.0\right\rfloor$

This adjusts the phase to be better approximated without resorting to Fourier decomposition. The amplitude is estimated in the same way as for the NICAM data.

\section{References}

Adler RF, Huffman GJ, Chang A, Ferraro R, Xie P-P, Janowiak J, Rudolf B, Schneider U, Curtis S, Bolvin D, Gruber A, Susskind J, Arkin P, Nelkin E (2003) The version-2 global precipitation climatology project (GPCP) monthly precipitation analysis (1979-present). J Hydrometeor 4:1147-1167

Bechtold P, Koehler M, Jung T, Doblas-Reyes F, Leutbecher M, Rodwell MJ, Vitart F, Balsamo G (2008) Advances in simulating atmospheric variability with the ECMWF model: from synoptic to decadal time-scales. Q J R Meteor Soc 134:1337-1351

Bosilovich MG (2008) NASA's modern era retrospective-analysis for research and applications: integrating earth observations. Available online at http://wwwearthzineorg/2008/09/26/nasasmodern-era-retrospective-analysis

Bosilovich MG, Chen J, Robertson FR, Adler RF (2008) Evaluation of global precipitation in reanalyses. J Appl Meteor Climatol 47:2279-2299

Bryan GH, Wyngaard JC, Fritsch JM (2003) Resolution requirements for the simulation of deep moist convection. Mon Wea Rev 10:2394-2416

Clark AJ, Gallus WA, Chen T-C (2007) Comparison of the diurnal precipitation cycle in convection-resolving and non-convectionresolving mesoscale models. Mon Wea Rev 135:3456-3473

Collins WD, Bitz CM, Blackmon ML, Bonan GB, Bretherton CS, Carton JA, Chang P, Doney SC, Hack JJ, Henderson TB, Kiehl JT, Large WG, McKenna DS, Santer BD, Smith RD (2006) The community climate system model version 3 (CCSM3). J Climate $19: 2122-2143$

Dai A (2006) Precipitation characteristics in eighteen coupled climate models. J Climate 19:4605-4630

Dai A, Giorgi F, Trenberth KE (1999) Observed and model-simulated diurnal cycles of precipitation over the contiguous United States. J Geophys Res 104:6377-6402

Ek MB, Holstlag AAM (2004) Influence of soil moisture on boundary layer cloud development. J Hydrometeor 5:86-99

European Centre for Medium-range Weather Forecasts (2009) IFS documentation-Cy33r1: operational implementation 3 June 2008. Available online at: http://www.ecmwf.int/research/ ifsdocs/CY33r1/index.html
Garreaud RD, Wallace JM (1997) The diurnal march of convective cloudiness over the Americas. Mon Wea Rev 125:3157-3171

Gochis DJ, Jimenez A, Watts CJ, Garatuza-Payan J, Shuttleworth WJ (2004) Analysis of 2002 and 2003 warm-season precipitation from the North American Monsoon Experiment event rain gauge network. Mon Wea Rev 132:2938-2953

Hack JJ (1994) Parameterization of moist convection in the National Center for Atmospheric Research Community Climate Model (CCM2). J Geophys Res 99:5551-5568

Holtslag AAM, Boville BA (1993) Local versus nonlocal boundarylayer diffusion in a global climate model. J Climate 6:1825-1842

Huffman GJ, Adler RF, Bolvin DT, Gu G, Nelkin EJ, Bowman KP, Hong Y, Stocker EF, Wolff DB (2007) The TRMM multi-satellite precipitation analysis: quasi-global, multi-year, combined-sensor precipitation estimates at fine scale. J Hydrometeor 8:38-55

Joyce RJ, Janowiak JE, Arkin PA, Xie P (2004) CMORPH: a method that produces global precipitation estimates from passive microwave and infrared data at high spatial and temporal resolution. J Hydrometeor 5:487-503

Jung T, Balsamo G, Bechtold P, Beljaars A, Koehler M, Miller M, Morcrette JJ, Orr A, Rodwell MJ, Tompkins AM (2010) The ECMWF model climate: recent progress through improved physical parametrizations. Q J R Meteor Soc 136:1145-1160

Khairoutdinov MF, Randall DA, DeMott CA (2005) Simulations of the atmospheric general circulation using a cloud-resolving model as a superparameterization of physical processes. J Atmos Sci 62:2136-2154

Kinter III JL, Cash B, Achuthavarier D, Adams J, Altshuler E, Dirmeyer PA, Huang B, Jin E, Marx L, Manganello J, Stan C, Wakefield T, Palmer T, Hamrud M, Jung T, Miller M, Towers P, Wedi N, Satoh M, Tomita H, Kodama C, Yamada Y, Andrews P, Baer T, Ezell M, Halloy C, John D, Loftis B, Wong K (2011) Revolutionizing climate modeling-project Athena: a multiinstitutional, international collaboration. Bull Am Meteor Soc (submitted)

Molteni F, Buizza R, Palmer TN, Petroliagis T (1996) The ECMWF ensemble prediction system: methodology and validation. Q J R Meteor Soc 122:73-119

Nakanishi M, Niino H (2006) An improved Mellor-Yamada level-3 model: its numerical stability and application to a regional prediction of advection fog. Bound Layer Meteorol 119:397-407

Nesbitt SW, Zipser EJ (2003) The diurnal cycle of rainfall and convective intensity according to three years of TRMM measurements. J Climate 16:1456-1475

Noda AT, Oouchi K, Satoh M, Tomita H, Iga S, Tsushima Y (2010) Importance of the subgrid-scale turbulent moist process: cloud distribution in global cloud-resolving simulations. Atmos Res 96:208-217

Oouchi K, Noda AT, Satoh M, Miura H, Tomita H, Nasuno T, Iga S-I (2009a) A simulated preconditioning of typhoon genesis controlled by a boreal summer Madden-Julian Oscillation event in a global cloud-resolving mode. Sci Online Lett Atmos 5:065068. doi:102151/sola2009017

Oouchi K, Noda AT, Satoh M, Wang B, Xie S-P, Takahashi H, Yasunari T (2009b) Asian summer monsoon simulated by a global cloud-system resolving model: diurnal to intra-seasonal variability. Geophys Res Lett 36:L11815. doi:101029/ 2009GL038271

Polcher J (2004) GMPP to focus on the diurnal cycle. GEWEX News 14(2):8

Reynolds RW, Smith TM, Liu C, Chelton DB, Casey KS, Schlax MG (2007) Daily high-resolution blended analyses for sea surface temperature. J Climate 20:5473-5496

Riley GT, Landin MG, Bosart L (1987) The diurnal variability of precipitation across the Central Rockies and adjacent Great Plains. Mon Wea Rev 115:1161-1172 
Sato T, Miura H, Satoh M, Takayabu YN, Wang Y (2009) Diurnal cycle of precipitation in the tropics simulated in a global cloudresolving model. J Climate 22:4809-4826

Satoh M, Matsuno T, Tomita H, Miura H, Nasuno T, Iga S (2008) Nonhydrostatic icosahedral atmospheric model (NICAM) for global cloud resolving simulations. J Comp Phys 227:3486-3514. doi:101016/jjcp200702006

Shukla J, Hagedorn R, Hoskins B, Kinter JL III, Marotzke J, Miller M, Palmer TN, Slingo J (2009) Strategies: revolution in climate prediction is both necessary and possible: a declaration at the world modelling summit for climate prediction. Bull Am Meteor Soc 90:175-178

Sorooshian S, Gao X, Hsu K, Maddox RA, Hong Y, Gupta HV, Imam B (2002) Diurnal variability of tropical rainfall retrieved from combined GOES and TRMM satellite information. J Climate 15:983-1001

Stan C, Khairoutdinov M, DeMott CA, Krishnamurthy V, Straus DM, Randall DA, Kinter JL III, Shukla J (2010) An ocean-atmosphere climate simulation with an embedded cloud resolving model. Geophys Res Lett 37:L01702. doi:101029/2009GL040822

Stubenrauch CJ, Chédin A, Rädel G, Scott NA, Serrar S (2006) Cloud properties and their seasonal and diurnal variability from TOVS Path-B. J Climate 19:5531-5553

Stull RB (1988) An introduction to boundary layer meteorology atmospheric and oceanographic sciences library, vol 13 . Springer, Berlin

Takata K, Emori S, Watanabe T (2003) Development of the minimal advanced treatments of surface interaction and runoff. Global Planet Change 38:209-222

Tao WK, Chern JD, Atlas R, Randall D, Khairoutdinov M, Li JL, Waliser DE, Hou A, Lin X, Peters-Lidard C, Lau W, Jiang J, Simpson J (2009) A multiscale modeling system: developments, applications, and critical issues. Bull Am Meteor Soc 90:515-534
Tian Y, Peters-Lidard CD, Choudhury BJ, Garcia M (2008) Multitemporal analysis of TRMM-based satellite precipitation products for land data assimilation applications. J Hydrometeor 8:1165-1183

Tiedtke M (1989) A comprehensive mass flux scheme for cumulus parameterization in large-scale models. Mon Wea Rev 117:1779-1800

Tomita H (2008) New microphysics with five and six categories with diagnostic generation of cloud ice. J Meteor Soc Japan 86A:121-142

Uppala SM et al (2005) The ERA-40 re-analysis. Quart J R Meteor Soc 131:2961-3012

Weisman ML, Skamarock WC, Klemp JB (1997) The resolution dependence of explicitly modeled convective systems. Mon Wea Rev 125:527-548

Wolff J-O, Maier-Reimer E, Legutke S (1997) The Hamburg Ocean primitive equation model HOPE. DKRZ series technical report 13 Deutsches Klimarechenzentrum. doi:102312/WDCC/DKRZ_ Report_No13

Wylie D (2008) Diurnal cycles of clouds and how they affect polarorbiting satellite data. J Climate 21:3989-3996

Zeweldi DA, Gebremichael M (2009) Evaluation of CMORPH precipitation products at fine space-time scales. J Hydrometeor 10:300-307

Zhang GJ (2003) Roles of tropospheric and boundary layer forcing in the diurnal cycle of convection in the U.S. southern Great Plains. Geophys Res Let 30:2281. doi:10.1029/2003GL018554

Zhang GJ, McFarlane NA (1995) Sensitivity of climate simulations to the parameterization of cumulus convection in the Canadian Climate Centre general circulation model. Atmos Ocean 33:407-446 